\title{
La cerámica tardía de Marcajirca, Conchucos, Áncash: lo que nos enseñan los estudios petrográficos
}

Les céramiques précoloniales de Marcajirca, Conchucos, Ancash: ce que nous révèlent les études pétrographiques

The late ceramics of Marcajirca, Conchucos, Ancash: What petrography tells us

Isabelle Druc

\section{(2) OpenEdition}

\section{Journals}

Edición electrónica

URL: http://journals.openedition.org/bifea/8014

DOI: 10.4000/bifea.8014

ISSN: 2076-5827

Editor

Institut Français d'Études Andines

\section{Edición impresa}

Fecha de publicación: 1 agosto 2016

Paginación: 327-352

ISSN: 0303-7495

\section{Referencia electrónica}

Isabelle Druc, «La cerámica tardía de Marcajirca, Conchucos, Áncash: lo que nos enseñan los

estudios petrográficos », Bulletin de l'Institut français d'études andines [En línea], 45 (2) | 2016, Publicado el 08 agosto 2016, consultado el 06 noviembre 2020. URL : http://journals.openedition.org/bifea/8014 ; DOI : https://doi.org/10.4000/bifea.8014

\section{(c) (i) $\odot$}

Les contenus du Bulletin de l'Institut français d'études andines sont mis à disposition selon les termes de la licence Creative Commons Attribution - Pas d'Utilisation Commerciale - Pas de Modification 4.0 International. 


\title{
La cerámica tardía de Marcajirca, Conchucos, Áncash: lo que nos enseñan los estudios petrográficos
}

\author{
Isabelle Druc*
}

\begin{abstract}
Resumen
El análisis petrográfico de cerámicas de Marcajirca, sitio de altura del Intermedio Tardío (10001474 d. C.) en Conchucos, Áncash, muestra una variabilidad de composición mineral que sugiere múltiples productores, el uso de varias fuentes y al menos dos procedencias distintas. Las pastas tienen un temperante de pizarra molida que se asemeja al material utilizado en la producción local tradicional. Una muestra presenta una pasta de origen distinto, regional o exógeno. Se postula una continuidad tecnológica de uso de las materias primas. Los datos etnográficos, arqueológicos y la situación geográfica de Marcajirca permiten proponer un escenario de adquisición de las vasijas posiblemente producidas en la zona de Yacya/Acopalca cerca de Huari, que hubiera podido abastecer a la región hasta el valle del Puccha.
\end{abstract}

Palabras clave: análisis cerámico, petrografía, arqueología andina, etnoarqueología

\section{Les céramiques précoloniales de Marcajirca, Conchucos, Ancash: ce que nous révèlent les études pétrographiques}

\section{Résumé}

L'analyse pétrographique de céramiques de Marcajirca, un site de I'Intermédiaire récent (10001474 ap. J.-C.) au Conchucos, département d'Ancash, dans les Andes nord-centrales du Pérou, nous a permis d'identifier différents groupes de production et aires d'approvisionnement. La plupart des céramiques présentent un dégraissant d'ardoise pilée et sont d'origine locale, sauf une céramique probablement d'origine exogène à la vallée. La comparaison avec du matériel de référence de production locale traditionnelle suggère une continuité technologique dans le choix du dégraissant. 
Les données archéologiques et ethnographiques permettent de proposer un scénario d'acquisition des pots plutôt qu'une production sur place. La région de Yacya/Acopalca, proche de Huari à 8 km du site de Marcajirca a probablement fourni en poterie la région, jusqu'à la rivière Puccha.

Mots-clés : analyse céramique, petrographie, archéologie andine, ethnoarchéologie

\title{
The late ceramics of Marcajirca, Conchucos, Ancash: What petrography tells us
}

\begin{abstract}
The petrographic analysis of ceramic materials from Marcajirca, a Late Intermediate Period site (1000-1474 A.D.) in Conchucos, highland Ancash, north-central Peru, allowed us to identify different production groups and resource areas. Most of the ceramics are tempered with crushed slate and are of local origin, except one that is probably exogenous to the valley. Comparison with reference material from traditional local production centers suggests a technological continuity in the choice of temper. Archaeological and ethnographic data allow us to propose an acquisition scenario for the pots rather than on-site production. The area of Yacya/Acopalca, near the town of Huari and located only $8 \mathrm{~km}$ away from Marcajirca was probably supplying the region up to the Puccha River with pottery.
\end{abstract}

Keywords: ceramic analysis, petrography, Andean archaeology, ceramic ethnography

\section{INTRODUCCIÓN}

Aunque se conozca bien la producción cerámica tradicional de Conchucos central (Druc, 2001; 2005; 2009; Ramón, 2013a; 2013b) y que la cerámica formativa de Chavín de Huantar fue el objeto de varios análisis de pasta (Druc, 1998; 2004; Marsh \& Druc, 2015), tenemos menos información sobre la composición y la producción cerámica en otras épocas para esta región. En los últimos 15 años, sin embargo, se desarrollaron muchas investigaciones que dieron a conocer los patrones de asentamiento, los estilos cerámicos y un mejor entendimiento de la complejidad social en Conchucos, en particular para el Intermedio Tardío (e.g. Ibarra, 2003; 2009; Herrera et al., 2006; Orsini \& Benozzi, 2013; ver también la reseña de literatura a continuación). El análisis de la composición de cerámicas de Marcajirca, un sitio del Intermedio Tardío ocupado hasta la época colonial (Ibarra, 2003; 2007) (figs. 1 y 2), tiene por meta aportar a este conjunto de datos una perspectiva más detallada sobre la producción cerámica y su distribución en este período para Conchucos central. Toma en cuenta los resultados de los estudios de las cerámicas de los sitios alrededor de la laguna de Puruhuay (en particular Ñawpamarca) (Orsini \& Benozzi, 2013) y de Huacramarca en la cuenca del Yanamayo (Vega Centeno, 2008; Vega Centeno et al., 2014), como los datos etnohistóricos y etnoarqueológicos para la zona. La organización de la producción cerámica y de la distribución de las vasijas en el Intermedio Tardío se vincula también con la problemática de las relaciones entre el grupo huari (Ibarra, 2006) y el grupo vecino pincos al sur del río Puccha (León Gómez, 2003). 




Figura 1 - Mapa de Áncash con los principales sitios mencionados en el texto

La región del Callejón de Conchucos figura en gris claro. En gris oscuro figura el Callejón de Huaylas abarcando las respectivas vertientes de las Cordilleras Blanca y Negra. En blanco se ve la región de los valles costeños y del litoral del departamento de Áncash

Reproducido con autorización de Druc (2005: 10, fig. 1) 




Figura 2 - Detalle de la región de Huari y Marcajirca, con curva de nivel de los 3000 m (línea acentuada en negro)

Mapa original elaborado por Bebel Ibarra, utilizado con autorización del autor y modificado por Isabelle Druc

Las cerámicas de Marcajirca representan un estudio de caso muy interesante, tanto desde el punto temporal, echando un puente entre los períodos preincaico e histórico, como desde el punto tecnológico y de la logística de producción y distribución. El carácter utilitario de esta cerámica y la falta de elementos diagnósticos, que también están mencionados en los trabajos de Orsini \& Benozzi (2013), dificultan su estudio estilístico. De allí la ventaja de los análisis de pasta que permiten establecer tipologías y entender mejor la producción cerámica. El análisis petrográfico de la pasta de 12 fragmentos de cerámica de Marcajirca tenía tres objetivos: 1) identificar los grupos cerámicos basados en la composición mineral; 2) indicar si se trata de producción local o no; 3) investigar los posibles lugares de producción y procesos de adquisición de las vasijas para un sitio de altura como Marcajirca. Adicionalmente se hizo un estudio exploratorio del temperante con microscopio electrónico de barrido. 
Se presenta primero una breve revisión de la literatura para Conchucos y el Callejón de Huaylas en relación con la problemática abordada. Siguen los datos arqueológicos, etnográficos y geológicos para la zona de Marcajirca y Huari, en Conchucos central, con enfoque hacia las materias primas disponibles y las estrategias de producción. Luego viene la presentación de los datos de análisis y su interpretación. La discusión presenta las líneas de investigación que permiten proponer una visión más regional de la producción cerámica y de su distribución en el Intermedio Tardío para el área de estudio, así como unas reflexiones acerca de la continuidad temporal de las tradiciones observadas.

\section{ANTECEDENTES}

Brevemente esbozada, la historia de Conchucos central sigue los desarrollos observados en otras partes de la sierra de Áncash después del declive de Chavín, pero con menos fuerza. La tradición tecnológica cerámica cambió después de Chavín con el uso de otras materias primas (Druc, 2001), registros decorativos y formas (Lau, 2004: 189; 2013: 30-32). En el Intermedio Temprano, la cultura Recuay prevalece en el Callejón de Huaylas, con su cerámica fina de caolín y su arte lítico e impacta las regiones adyacentes, como en Conchucos, en la cuenca y valle del Yanamayo (Lau, 2002; 2004; 2010; Wegner, 2000; 2011). El Horizonte Medio está marcado por la influencia Wari que afecta los patrones socioculturales y los estilos cerámicos en el Callejón de Huaylas y la Cordillera Negra, hasta reemplazar la tradición cerámica local por estilos derivados Wari (Lau, 2002: 300; 2005: 82-83, 90). Esta influencia no se hace sentir tanto en Conchucos y no se identificó cerámica Wari per se (Herrera, 2003: 238; Ibarra, 2003: 274-275, 312317). Para el Intermedio Tardío en Conchucos tenemos más informaciones sobre el registro cerámico y los patrones de ocupación gracias a los trabajos de varios investigadores en la región de Huari, del río Puccha y en la cuenca del Yanamayo (Ibarra, 2003; 2006; 2007; Orsini, 2005; Orsini \& Benozzi, 2013; Herrera, 2003; Herrera et al., 2006; Vega Centeno, 2008; Vega Centeno et al., 2014). Estos trabajos revelaron una ocupación extendida de sitios de altura con estructuras defensivas, varios de los cuales siguieron en uso hasta las épocas Inca y colonial (Diessl, 2004; Ibarra, 2003; 2006; Orsini \& Benozzi, 2013). La localización y los elementos defensivos de los sitios del Intermedio Tardío en Conchucos apuntan a un clima de inseguridad o de lucha entre grupos regionales (Mantha, 2006). Ibarra observa que los sitios en cumbre de montaña están asociados con zonas de cultivos particulares, en relación con una cierta ecología y tipo de suelo, siendo Marcajirca zona de alta producción de alverjas (Ibarra, 2003: 294).

La cerámica por lo general es de carácter común y utilitario, de manufactura gruesa. Predominan las jarras, cántaros y ollas, y en menor cantidad los cuencos. Pocos fragmentos presentan elementos diagnósticos. Varios estilos relacionados entre sí conforman la cerámica del Intermedio Tardío en la sierra de Áncash: Aquilpo en el Callejón de Huaylas por Amat y Espejo (en Lanning, 1965), Chakwas (del sitio de Chinchawas en la Cordillera Negra) y Pojoc (y Waman Wain) en las 
alturas cercanas a Chavín de Huantar, en la cuenca del río Mosna, en Conchucos (Burger, 1982; Burger \& Salazar, 2015: 48; Lau, 2010: 264-271). En general la cerámica tardía tipo Aquilpo que se encuentra en la Cordillera Negra, el Callejón de Huaylas y Conchucos, se caracteriza por una decoración incisa en forma de círculos, círculos en ondas, círculos en bandas aplicadas todas alrededor del cuello de la vasija o la parte superior del cuerpo (Ibarra, comunicación personal, 2015; ver Lau, 2004: 189 para una presentación de este estilo).

Alrededor de la laguna de Puruhuay, en las alturas de Huari, un conjunto de sitios fueron investigados por Ibarra $(2003$; 2009) y desde 2006 por un equipo ítalo-peruano (ver Orsini \& Benozzi, 2013). Son sitios de altura, de carácter ritual para dos de ellos (Ishla Ranra de ocupación larga y Llamacorral del Horizonte Medio), y residencial y ceremonial para los sitios más recientes de Ñawpamarca de Huamantanga, Awilupacha, Ñawpamarca de Acopalca y Antaraga (Orsini \& Benozzi, 2013: 30-32, 34-38, 44-72, 113-116). Marta Porcedda estudió la cerámica de Ñawpamarca de Huamantanga, del Intermedio Tardío y de un pequeño sitio vecino (Awilupaccha), brindando importantes informaciones sobre la composición de las pastas de la zona de Puruhuay (Porcedda, 2013). La cerámica de Ñawpamarca se relaciona con el estilo Aquilpo por sus decoraciones incisas y su carácter grueso y utilitario (Porcedda, 2013: 95). Estas informaciones junto con el presente análisis permiten proponer unas hipótesis de producción cerámica para este período en la región de Huari.

En la zona de Huari, también se llevó a cabo un análisis de pasta de carácter etnohistórico y etnoarqueológico (Druc, 2001; 2005) que permitió distinguir dos tradiciones cerámicas antiguas en relación con las parcialidades del grupo preincaico huari: Ichochuari y Allaucahuari (Druc, 2009). Otro estudio comparativo de interés es el de Rafael Vega Centeno et al. (2014) sobre la cerámica del Intermedio Tardío de Huacramarca, un sitio de altura cerca de Chacas, en la cuenca del río Yanamayo. La cerámica fue analizada a nivel macroscópico y con análisis de difracción de rayos X, fluorescencia de rayos X y Espectroscopía Mössbauer. Los resultados de estos estudios se incorporan a la discusión más adelante.

\section{DATOS ARQUEOLÓGICOS}

El sitio de Marcajirca, excavado por Bebel Ibarra (2003; 2006; 2007; 2009), se sitúa en el distrito de Cajay, provincia de Huari, a 8 km de Huari capital provincial (figs. 1 y 2). Es una marca defensiva de puna ocupada desde el Intermedio Tardío (1000-1474 d. C.) con una fecha de 1040 d. C. obtenida en el sector residencial; continúa hasta el final de la época colonial en los años 1640 (Ibarra, 2003). Marcajirca cubre una superficie de 40 hectáreas sobre un promontorio a 3800 msnm, en la vertiente este del valle del río Huaritambo (fig. 3). Este río se une al río Mosna en Pomachaca, 1500 m más abajo de Marcajirca, para formar el río Puccha. Tiene un sector ceremonial o público en la parte alta, un sector funerario con chullpas y tumbas debajo de rocas y un sector residencial a continuación del sector funerario (Ibarra, 2003; 2007). Dos caminos unen el sitio al valle, 


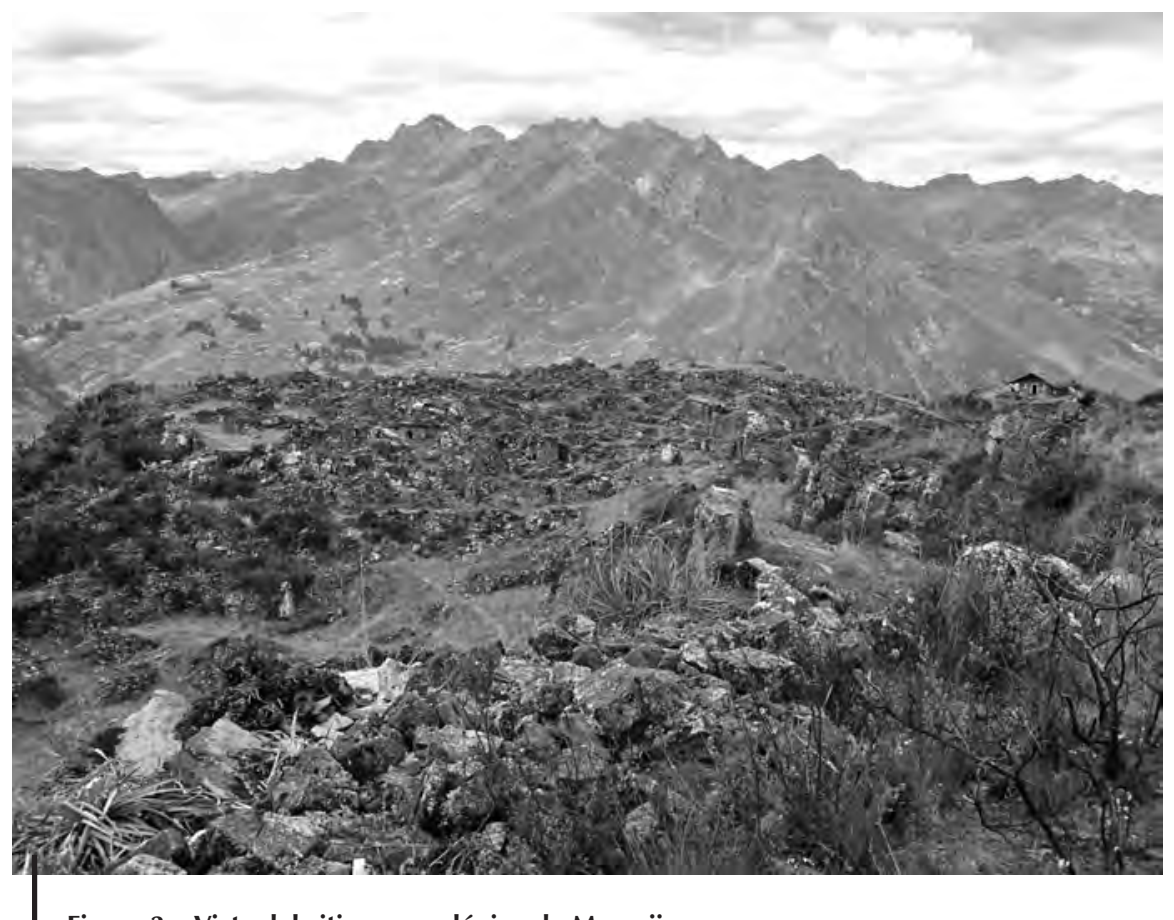

Figura 3 - Vista del sitio arqueológico de Marcajirca

(C) Isabelle Druc (2007)

probablemente para juntarse con el camino Inca que pasaba más abajo (Ibarra, 2009). El sitio está protegido por una muralla en la parte sur.

Como para muchos sitios de la región y de esta época, el material cerámico de Marcajirca consiste en vasijas domésticas, jarras, cántaros, ollas y cuencos, de ejecución tosca, sin pulido o engobe (figs. 4 y 5) (Ibarra, 2003; 2007). A veces se observa una decoración incisa o aplicada en banda. También existen unas pocas cerámicas más finas, para uso ceremonial o funerario (Ibarra, 2003; 2007). La cerámica con decoración pintada se aplica sobre un fondo blanco-crema con una pintura de color marrón (Ibarra, comunicación personal, 2015). La cerámica de Marcajirca corresponde al esquema formal y decorativo general para la cerámica del Intermedio Tardío de la sierra de Áncash. Para Conchucos central, Ibarra (2003: 318-320) identificó tres tipos estilísticos: Alisado Tosco y Fino, Negro Grafitado y Llano Blanco. Los tipos Negro Grafitado y Llano Blanco tienen paralelos decorativos con la cerámica Pojoc en la cuenca del Mosna, en las alturas de Chavín de Huantar, y el tipo Alisado Tosco con la cerámica Pojoc, Chincawasfase Chakwas en la Cordillera Negra y la cerámica de la cuenca del Yanamayo en la región de Chacas-San Luis (Ibarra, 2003: 318-320). El tipo grafitado es el más común en Marcajirca. Corresponde al Grupo 1 de cerámica gruesa de Ñawpamarca estudiado por Porcedda (2013). 


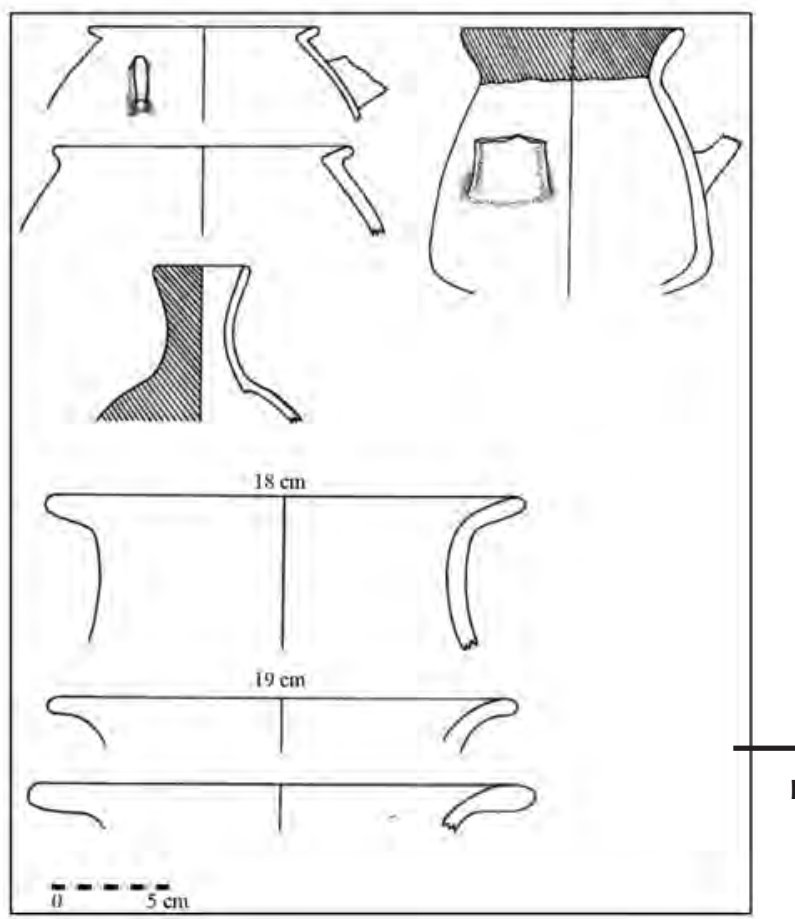

Figura 4 - Ejemplos de formas de vasijas de Marcajirca

Dibujos de Bebel Ibarra, reproducidos con autorización del autor

\section{DATOS ETNOGRÁFICOS: LA PRODUCCIÓN CERÁMICA TRADICIONAL}

En el área de estudio, los pueblos de Yacya y Acopalca son centros de producción alfarera, aunque de manera reducida ahora. Un tercer pueblo, Mallas, era conocido por su cerámica hasta hace unos 30 años (Druc, 1996; 2005; Ramón, 2013a). Estos pueblos se localizan entre 8 y $10 \mathrm{~km}$ (distancia geodésica) de Marcajirca (fig. 2), con una zona de extracción de materias primas ubicada hasta seis horas a pie del lugar de producción, en la Cordillera Blanca, cerca de los cerros Ventanillas y Mataderos (Druc, 2005). No existe otra zona alfarera en la cuenca del Puccha y la fama de estos tres pueblos, en cuanto a su producción cerámica, es mencionada en documentos etnohistóricos (Márquez Zorrilla, 1965; Matos Colchado, 2000). Mallas y Yacya tienen una ocupación larga que data por lo menos del Intermedio Tardío (Ibarra, 2003) mientras que Acopalca fue fundado en 1562 como obraje textil, aunque también era un lugar de producción alfarera (Márquez Zorrilla, 1965; Venturoli, 2009).

Yacya se encuentra a $4 \mathrm{~km}$ al sur de Huari, Acopalca a $2 \mathrm{~km}$ al noroeste. La producción cerámica es ahora limitada a unas pocas semanas en julio y agosto y pocas familias participan en ella. Son las mujeres quienes elaboran las ollas con la técnica del enrollado, ayudadas por hombres de la familia o peones para buscar y preparar los materiales. Las herramientas son pocas y simples: unos platos de 
La cerámica tardía de Marcajirca, Conchucos, Áncash: lo que nos enseñan los estudios petrográficos
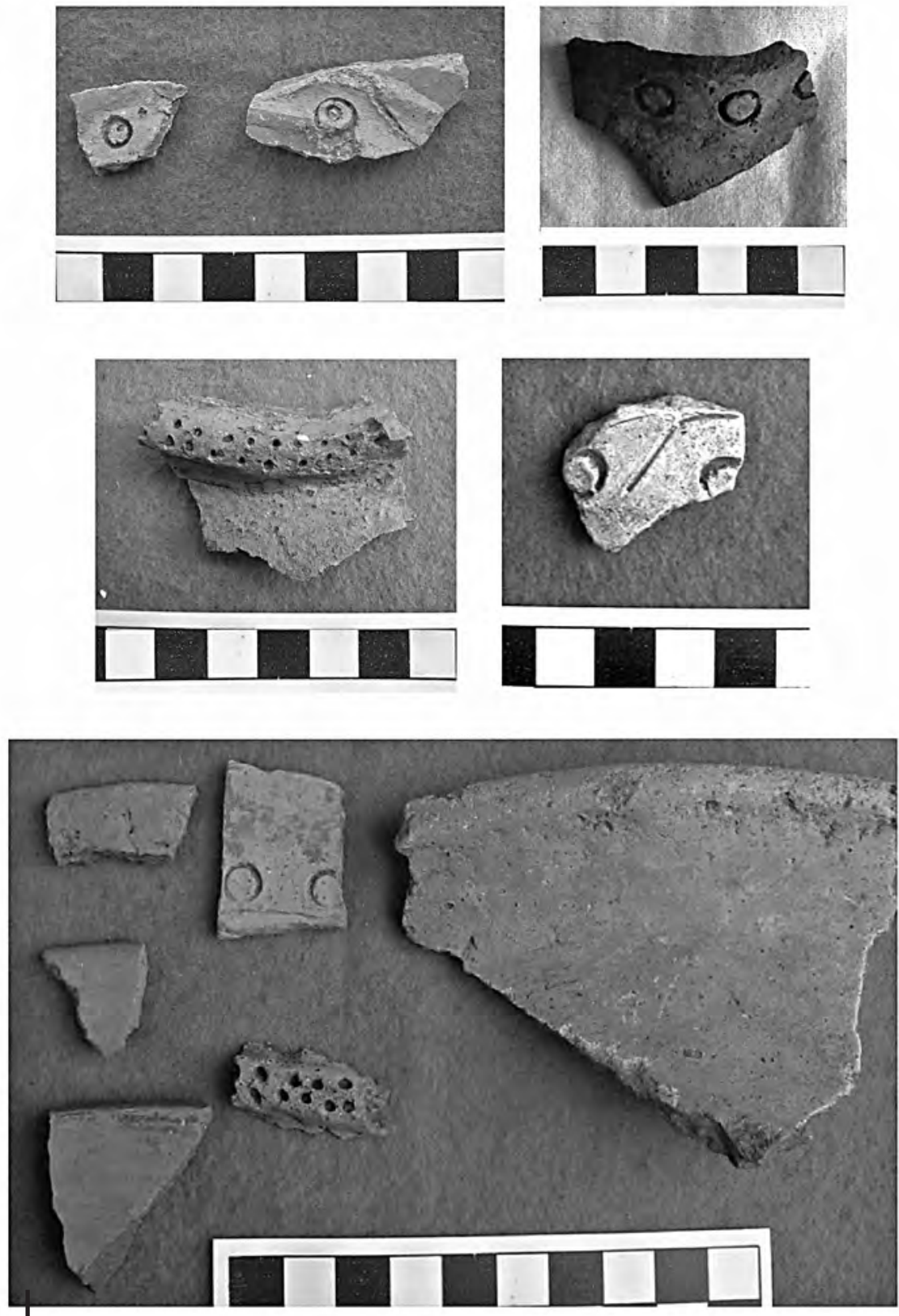

Figura 5 - Ejemplos de cerámica de Marcajirca, sector residencial

(c) Bebel Ibarra (2006), reproducido con autorización del autor 
alfarero de barro o madera de 10 a 12 centímetros de diámetro, una cojonta de maíz, un cuchillo de madera, un pedazo de mate y un trapo. El lugar de producción es el patio de la casa de la alfarera y la quema se hace en el campo en un pozo poco hondo. Para ello se busca los servicios de un especialista, el tambero (Druc, 2005).

El temperante utilizado en la zona de Huari es un tipo de pizarra molida llamado shashal, que tiene de 52,76\% a 55,52\% de carbón (Druc, 2001). Se extrae de unas minas en las alturas de Acopalca en la puna. Las vetas de pizarra varían en calidad dentro de una misma cueva en función del grado de metamorfismo de la roca y de la altura de la veta explotada. Actualmente no existen estudios geológicos sobre la variabilidad de esta roca a nivel local y regional. La pizarra molida se agrega en cantidad de uno por uno a la arcilla extraída de campos situados a 15 minutos al norte de Yacya o a una hora del lugar de producción. Se utilizan las mismas canteras o zona de extracción en Yacya y Acopalca. Cabe notar que la producción puede ser itinerante: existe la costumbre de contratar a una alfarera para que produzca en otra casa o pueblo (ver Ramón, 2013a para una discusión extendida sobre el tema).

Al nivel interpretativo de los datos, el uso de las mismas canteras o zona de extracción por las alfareras de Yacya y Acopalca impide distinguir un pueblo productor del otro. Así, la zona de producción del punto de vista composicional incluye los dos pueblos, una zona de unos $12 \mathrm{~km}$ de largo, incluyendo la zona de recursos. Las minas de shashal explotadas en la altura de Acopalca son las minas Matadera, Ventanilla y Socabón en la puna, entre 3 y 6 horas a pie desde Yacya o Acopalca. Otras minas más cercanas se agotaron o ya no son utilizadas. En el caso de una producción móvil, el problema para el arqueólogo es saber si la alfarera (o el alfarero) llevaba las materias primas con ella o solo sus herramientas. En la tradición actual de Yacya y Acopalca, la alfarera solo viaja con sus herramientas. El poblado o la familia que la comisiona es responsable de obtener y preparar los materiales y los servicios del tambero. En este caso, la pasta tiene un carácter local (del lugar donde se fabrica la cerámica). En otras zonas, y en particular cuando la distancia es mayor a un día de camino, el alfarero itinerante puede llevar su arcilla y temperante consigo (Druc, 2011; Ramón, 2013a).

Otros factores a considerar para la interpretación de los datos es la topografía. El río Huaritambo separa los pueblos ubicados en las dos vertientes de su valle. Yacya se sitúa casi frente a Marcajirca, a unos 4,5 $\mathrm{km}$ de distancia a vuelo de pájaro, en la vertiente oeste (lado de la Cordillera Blanca). Marcajirca se ubica en la ladera este. Ambos sitios se encuentran a dos horas a pie del fondo del valle del Huaritambo y la pendiente es fuerte. Estos factores deben ser considerados en los escenarios de distribución de la cerámica, tanto hoy como para épocas antiguas. El río Puccha a su vez marcaba un división territorial entre los grupos prehispánicos huari, al norte, y pincos, al sur. 


\section{DATOS GEOLÓGICOS}

Cuerpos intrusivos del batolito de la Cordillera Blanca y formaciones sedimentarias del Jurásico superior (Formación Chicama) y del Cretáceo inferior (Formación Oyón y grupo Goyllarisquizga) caracterizan la geología local (Cobbing et al., 1981; 1996; Egeler \& De Booy, 1956). Capas metamórficas con pizarra y cuarcita e intrusiones volcánicas de tipo andesita también afloran en la zona (Diessl, 2004: 14-15). Niveles de carbón y lutitas gris oscuro se encuentran en la sección inferior de la Formación Chimú del Cretáceo, de ambos lados lados de la Cordillera Blanca (Cobbing et al., 1981). Las formaciones sedimentarias cuentan con lutitas gris oscuro, limonitas, cuarcitas, pizarras y tufos (Formación Chicama), lutitas, pizarras negras, depósitos de carbón, calizas, cuarcitas y areniscas (Formación Oyón y grupo Goyllarisquizga) (Cobbing et al., 1996). Depósitos aluviales y glaciares del Cuaternario se encuentran en el fondo de los valles. El cuerpo intrusivo principal del batolito es de tipo leucogranodiorita (con cuarzo, feldespato potásico, biotita y muscovita), conocido como el cuerpo Cohup (Cobbing et al., 1981; Egeler \& De Booy, 1956) que se extiende desde Chavín de Huantar hasta Corongo, al oeste del río Huaritambo. Este cuerpo se encuentra colocado dentro de pizarras de la Formación Chicama (Cobbing et al., 1981). Lentes de arcillas micáceas y expandibles de tipo ilita-montmorillonita existen en la región (Ing. geólogo Pérez Carpio, comunicación personal, 1998).

\section{DATOS DE ANÁLISIS}

Se analizaron 12 muestras cerámicas de estructuras en el sector funerario de Marcajirca, elegidas por Bebel Ibarra a fin de obtener una selección representativa de los tipos cerámicos del sitio (cuadro 1). Las formas y estilos presentes en los sectores residencial y funerario son similares (Bebel Ibarra, comunicación personal, octubre de 2015). Los fragmentos elegidos no presentan carácter estilístico particular y se parecen en cuanto al acabado. Bebel Ibarra los identificó como del Intermedio Tardío o de época Inca por la estructura y la unidad en la cual se encontraban y los fechados asociados a estas estructuras. Es interesante notar que los análisis petrográficos confirman de un cierto modo esta identificación temporal (ver discusión más adelante). Los fragmentos analizados provienen de ollas y jarras domésticas. Las muestras (Ma1 a Ma12) fueron preparadas en láminas delgadas para su análisis petrográfico. El material de referencia consiste en fragmentos de cerámica tradicional y de materias primas, colectado anteriormente para un estudio de la producción cerámica tradicional en Conchucos (Druc, 1996; 2001; 2005).

El análisis macroscópico de la cerámica de Marcajirca hecho por Bebel Ibarra y los investigadores que trabajaron en el sitio revela que la mayoría de las pastas tiene un desgrasante negro, tosco, con fragmentos visibles al ojo. Deja una marca negra al raspar un fragmento sobre una hoja blanca, de ahí el nombre de cerámica grafitada (lbarra, 2003: 318). 
Cuadro 1 - Procedencia de las muestras arqueológicas analizadas (PG Petrogrupo)

\begin{tabular}{|c|c|c|c|}
\hline Muestras & PG & Estructura y Unidad & Unidad estratigráfica \\
\hline Ma1 & 1 & V-I & 1 Intermedio Tardío \\
\hline Ma2 & 1 & V-I & 3 Intermedio Tardío \\
\hline Ma3 & 3 & CH-I & 3 Inca \\
\hline Ma4 & 1 & IV-1A & 5 Intermedio Tardío \\
\hline Ma5 & 3 & III-I & 1 Inca \\
\hline Ma6 & 1 & III-1 & 6 Inca \\
\hline Ma7 & 1 & V-1A & 1 Intermedio Tardío \\
\hline Ma8 & 2 & V-1 & 5 Intermedio Tardío \\
\hline Ma9 & 2 & IV-1 & 2 Inca \\
\hline Ma10 & 4 atípico & III-1 & Intermedio Tardío \\
\hline Ma11 & 2 & IV-1A & Inca \\
\hline Ma12 & 3 & III-2A & \\
\hline
\end{tabular}

El análisis petrográfico se hizo con microscopio Leitz en el departamento de Geología de la Universidad de Wisconsin-Madison y con un microscopio Nikon en el departamento de Antropología para el análisis granulométrico, con magnificación de X4 a X20 según los casos. Para el análisis granulométrico se usó la escala de Udden-Wentworth con los siguientes límites de clases granulométricas: arena fina $(0,125-0,25 \mathrm{~mm})$, arena mediana $(0,26-0,50 \mathrm{~mm})$, arena gruesa $(0,51-$ $1 \mathrm{~mm})$, arena muy gruesa (1-2 mm), grava (2-4 mm) (Folk, 1965). El análisis toma en cuenta: a) la composición mineral de las inclusiones en la pasta; b) la granulometría de las inclusiones; c) su distribución; y d) la textura de la pasta. Estos criterios permitieron una primera clasificación de las láminas delgadas. Las láminas son clasificadas en petrogrupos en función de la composición, granulometría de las inclusiones, su distribución y la textura de la pasta. El nombre de cada petrogrupo refleja el mineral dominante en la pasta. Existen variaciones cuantitativas internas en el porcentaje de inclusiones y minerales menores. El término de shashal se refiere a los fragmentos de pizarra.

\section{RESULTADOS DE LOS ANÁLISIS PETROGRÁFICOS DE LA CERÁMICA DE MARCAJIRCA}

- Petrogrupo 1: Temperante grueso a muy grueso de shashal. Láminas Ma1, Ma2, Ma4, Ma6, Ma7 (fig. 6A). Muestras del Intermedio Tardío, menos Ma6, de época Inca.

- Componente mayor: shashal con mayoría de fragmentos de tamaño grueso a muy grueso. 
A



C

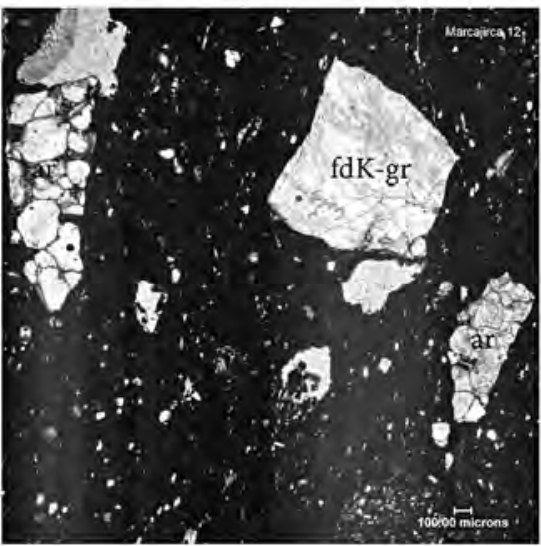

E

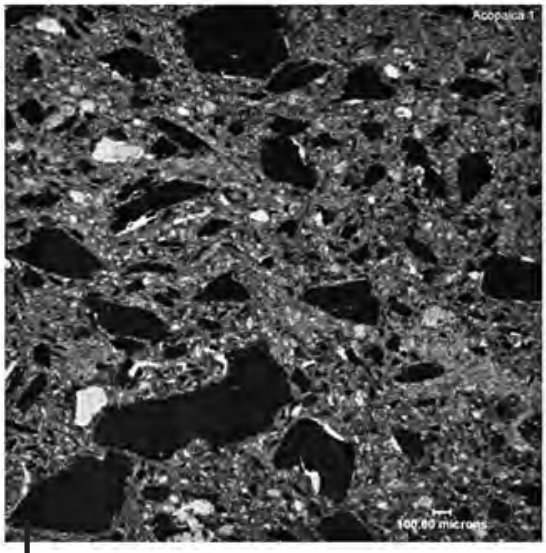

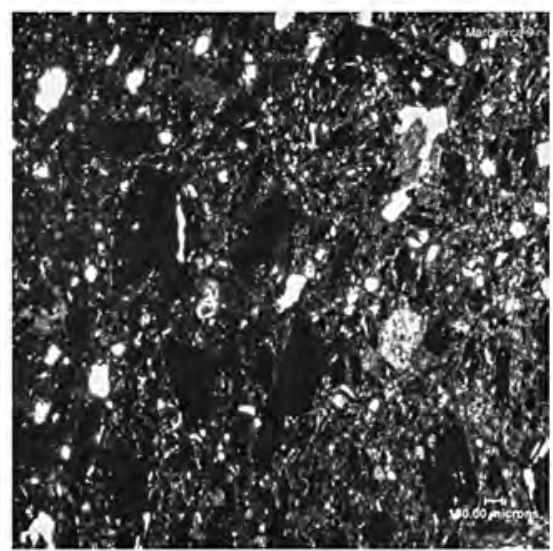
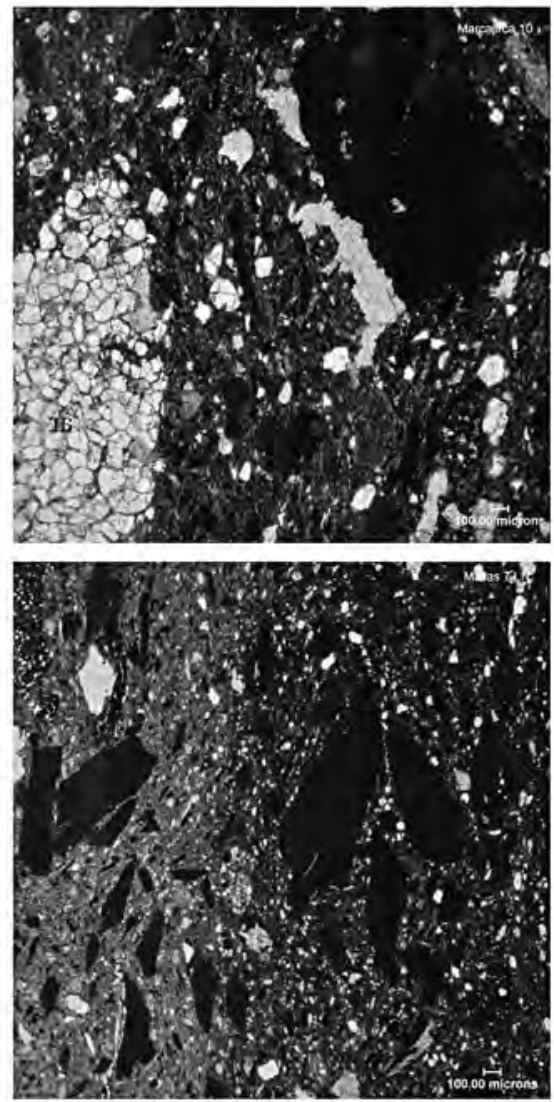

Figura 6 - Pastas de Marcajirca: A) Petrogrupo 1, MA6. Las líneas verticales vienen de una falla al cubrir la lámina; B) Petrogrupo 2, MA9; C) Petrogrupo 3, MA5; D) Petrogrupo 4, MA10; E-F) Pastas de cerámica tradicional, temperada con shashal (fragmentos negros alargados); E) Pasta de Acopalca; F) Pasta de Mallas Todas las fotomicrografías fueron tomadas por I. Druc, a $5 \mathrm{X}$ con nícoles paralelos arenisca (ar), feldespato potásico (fdK), granito (gr) 
- Componente menor: cristales de cuarzo y feldespatos, lutita, arenisca cuarzosa y arenisca arcosa.

- Granulometría: muy fina a muy gruesa, algunas inclusiones de tamaño de las gravas.

- Distribución: inhomogénea y sin distribución particular.

- Textura de la pasta: variable, compacta a poca compacta (con cavidades).

- Color de la matriz: morena a gris oscuro en nícoles paralelos.

Las láminas Ma2 y Ma7 contienen menos shashal pero la composición mineral es la misma que para las otras láminas de este grupo. Ma1 presenta una composición más sedimentaria que las otras láminas.

- Petrogrupo 2: Temperante mediano a grueso de shashal. Láminas Ma8, Ma9, Ma11 (fig. 6B). Muestras del Intermedio Tardío.

- Componente mayor: shashal con mayoría de fragmentos de tamaño mediano a grueso.

- Componente menor: cristales de cuarzo y feldespato, lutita y arenisca arcosa.

- Granulometría: muy fina a muy gruesa con numerosos granos de tamaño mediano.

- Distribución: inhomogénea y sin distribución particular.

- Textura de la pasta: variable, compacta a poco compacta (con cavidades).

- Color de la matriz: morena a gris oscuro en nícoles paralelos.

Ma8 presenta una granulometría gruesa a muy gruesa. M9 tiene una composición más sedimentaria que las otras láminas de este grupo.

- Petrogrupo 3: Temperante de shashal y fragmentos líticos de origen mixto en la matriz. Láminas Ma3, Ma5, Ma12 (fig. 6C). Muestras de época Inca.

- Componente mayor 1: shashal de tamaño fino a grueso.

- Componente mayor 2: fragmentos de rocas metamórfica y sedimentaria (cuarzita, arenisca arcosa, arenisca litosa, limonita, nódulos de arcilla), cristales de cuarzo y feldespatos alcalinos (pertitas) de origen granítica, micas blancos y óxidos.

- Granulometría de las inclusiones minerales: muy fina a gruesa.

- Granulometría de los fragmentos de roca: mediana a gruesa.

- Distribución: homogénea, inclusiones paralelas a los bordes.

- Textura de la pasta: variable, compacta a poca compacta.

- Color de la matriz: anaranjada a morena en nícoles paralelos. 
La cerámica tardía de Marcajirca, Conchucos, Áncash: lo que nos enseñan los estudios petrográficos

- Petrogrupo 4: Temperante de origen granítico y sedimentario con shashal en la matriz. Lámina Ma10, época Inca (fig. 6D)

- Componente mayor: inclusiones de origen granítico de tamaño mediano a grueso.

- Componentes menores: fragmentos de rocas metamórficas (cuarzitas) y sedimentarias detrítica (arenisca arcosa, arenisca), numerosos cristales de cuarzo y feldespato alcalino alterado, hornablenda y piroxeno alterados. Fragmentos finos a medianos de shashal en la matriz.

- Granulometría: muy fina a gruesa.

- Distribución: homogénea, inclusiones paralelas a los bordes.

- Textura de la pasta: compacta.

- Color de la matriz: oscura en nícoles paralelos.

El cuadro 2 presenta una clasificación de las láminas en relación con su composición lítica y la granulometría de los fragmentos de roca.

Cuadro 2 - Clasificación de las láminas en función del análisis modal de las inclusiones líticas rocas: sedimentarias (rs), detríticas (rsd) o clásticas (rsc), intrusivas (ri), metamórficas (rm)

\begin{tabular}{|c|c|c|c|c|c|}
\hline \multicolumn{6}{|c|}{ Fragmentos líticos } \\
\hline Granulometría & $\begin{array}{l}\text { Limonitas- } \\
\text { lutitas } \\
\text { (rsc) }\end{array}$ & $\begin{array}{c}\text { Inclusiones } \\
\text { graníticas } \\
\text { (ri) }\end{array}$ & $\begin{array}{l}\text { Areniscas } \\
\text { fedelsp. } \\
\text { (rsd) }\end{array}$ & $\begin{array}{c}\text { Areniscas } \\
\text { cuarzosas } \\
\text { (rs) }\end{array}$ & $\begin{array}{c}\text { Lutita/pizarra } \\
\text { (shashal) } \\
\text { (rs/rm) }\end{array}$ \\
\hline arena fina & Ma3, Ma5 & & & & Ma1 a Ma12 \\
\hline $\begin{array}{c}\text { arena } \\
\text { mediana }\end{array}$ & $\begin{array}{l}\text { Ma3, Ma4, } \\
\text { Ma5, Ma6, } \\
\text { Ma8, Ma9 }\end{array}$ & Ma10 & $\begin{array}{l}\text { Ma2, } \\
\text { Ma8 }\end{array}$ & $\begin{array}{l}\text { Ma5, } \\
\text { Ma6, } \\
\text { Ma10 }\end{array}$ & Ma1 a Ma12 \\
\hline arena gruesa & $\begin{array}{l}\text { Ma3, Ma4, } \\
\text { Ma5, Ma6, } \\
\text { Ma8, Ma9 }\end{array}$ & Ma10 & $\begin{array}{l}\text { Ma9, } \\
\text { Ma12 }\end{array}$ & $\begin{array}{c}\text { Ma2, } \\
\text { Ma5, } \\
\text { Ma6, } \\
\text { Ma10, } \\
\text { Ma12 }\end{array}$ & $\begin{array}{c}\text { Ma1 a Ma9 } \\
\text { Ma11 }\end{array}$ \\
\hline $\begin{array}{c}\text { arena muy } \\
\text { gruesa }\end{array}$ & Ma3, Ma4 & & & Ma4 & $\begin{array}{l}\text { Ma1, Ma3, } \\
\text { Ma4, Ma6, } \\
\text { Ma11 }\end{array}$ \\
\hline grava & Ma1 & & & & Ma1, Ma6 \\
\hline
\end{tabular}




\section{COMPOSICIÓN DEL SHASHAL: ANÁLISIS CON EL MICROSCOPIO ELECTRÓNICO DE BARRIDO (MEB)}

Un análisis exploratorio con el MEB se llevó a cabo con una muestra de Marcajirca y una muestra de olla moderna de Yacya para averiguar la composición química del shashal en la pasta cerámica y su variabilidad composicional interna, analizando varios fragmentos de shashal en la misma lámina. El MEB permite un análisis fino, focalizando el haz de electrones hacia el área o el grano de interés. Se puede obtener informaciones para elementos mayores, con recombinación en óxidos con un programa interno. John Fournelle, del laboratorio del MEB del departamento de Geología de la Universidad de Wisconsin-Madison, operó el microscopio. Se analizaron las muestras con análisis puntual (back scattering mode), focalizándose en los fragmentos de shashal sin incluir la matriz arcillosa, 30 segundos, con voltaje de aceleración de 15 Kev y magnificación de 200X a 400X, utilizando estándares y programas internos. Se observa una diferencia de compactación del shashal entre los fragmentos de shashal de la muestra de Marcajirca y los de Yacya.

En cuanto a la composición, los porcentajes de carbón varían entre 43\% y 58\% para Marcajirca y entre $49 \%$ y 59\% para Yacya para una cerámica hecha con shashal de Acopalca. Esto indicaría una misma área de procedencia para el temperante de estas dos muestras, que vendrían a ser las alturas de Acopalca, y no la mina en las alturas de Yacya que tiene un porcentaje de carbón mucho más alto (75,22\% según el análisis de carbón) (Druc, 2001). Sin embargo, esto indicaría el uso de temperante de las minas de Acopalca y no de Yacya. Esta hipótesis tiene que ser confirmada con informaciones detalladas en cuanto a las variaciones internas de composición de la pizarra dentro de una misma mina y al nivel regional con análisis de más fuentes. La diferencia de textura y menores variaciones de composición de los fragmentos podrían indicar el uso de distintas minas dentro de los niveles de pizarra de esta zona de la Cordillera Blanca.

\section{DISCUSIÓN DE LOS RESULTADOS DEL ANÁLISIS PETROGRÁFICO}

El análisis petrográfico y la clasificación de las láminas en el cuadro 2 permiten observar diferencias tecnológicas y de tradición alfarera. Se detallan en los 6 puntos a continuación:

- Preparación gruesa de la pasta: las láminas Ma1, Ma3, Ma4, Ma6 y Ma11 presentan una pasta gruesa a muy gruesa, con algunas inclusiones del tamaño de las gravas. La granulometría sugiere que el temperante no fue bien molido, o molido rápidamente y que el tamaño de las inclusiones no tiene importancia o incidencia para la función o apariencia de las vasijas. Este tratamiento vale para una producción de uso doméstico, para ollas de cocina y jarras.

- Tradición con shashal: la mayoría de las láminas de Marcajirca presentan hasta $50 \%$ de shashal (estimación visual) en una pasta de origen detrítica sedimentaria, 
una receta que corresponde a las observaciones etnográficas para la producción tradicional actual en la región de Huari donde el ratio arcilla:temperante es de 1:1 (Druc, 2005). Esta receta también caracteriza a las pastas analizadas del Intermedio Tardío de Marcajirca.

- Diferencias entre Intermedio Tardío y época Inca: los petrogrupos 1 y 2 reagrupan las muestras del Intermedio Tardío, que se caracterizan por el uso de un temperante de shashal fino a muy grueso. Ma6 de época Inca se junta con las muestras del Petrogrupo 1. Las otras muestras de época Inca Ma3, Ma5, Ma10 y Ma12 se distinguen por la presencia de shashal y de fragmentos líticos metamórficos y sedimentarios (cuarzitas, areniscas, lutitas) y minerales sueltos desprendidos de estas rocas. Ma3, Ma5 y Ma12 constituyen el Petrogrupo 3. La presencia de temperante de shashal apunta a un origen de la región de Huari, pero los numerosos fragmentos de rocas silíceas sugieren que el sedimento arcilloso utilizado no proviene de las mismas fuentes que en la época anterior. El fragmento cerámico Ma10 presenta una composición granítica que lo distingue de los demás y sugiere un área de procedencia fuera del valle o un productor más cerca de fuentes con sedimentos detríticos graníticos. La presencia de shashal en la pasta indica, sin embargo, que estamos frente a un uso tradicional típico de Conchucos central.

- Producción diversificada: se notan pequeñas diferencias de composición de los minerales menores, granulometría y textura dentro de los petrogrupos, lo que sugiere diferencias de preparación de la pasta o un material de base variable al cual se agrega el temperante de shashal. Puede indicar el uso de vetas o minas distintas dentro del área de aprovisionamiento habitual, una variabilidad composicional dentro de la misma cantera, la existencia de diferentes talleres o distintas producciones a nivel temporal. Es decir, según los años o las producciones, un alfarero puede alterar un poco su receta si es que no tiene el material adecuado o acceso a la cantera habitual, lo cual resulta en un cambio composicional en la pasta. Lo ilustra el caso de Nicanor Zaavedra en el Callejón de Huaylas que a veces utiliza tres tierras y otras utiliza cuatro (Druc, registro de datos personales). Desde luego, un conocimiento de la geología local y de los recursos disponibles es importante, ya que permite evaluar la variabilidad composicional al nivel local.

- Competencia de producción: se notan diferencias de ejecución del trabajo, tanto en la preparación como en la manufactura. Una frecuencia baja de producción, por ejemplo en caso de producción doméstica, ocasional o estacional, genera productos: a) menos estandardizados que las producciones de alto volumen en un taller especializado (Roux, 2003); b) pastas inhomogéneas o variables en cuanto a la composición o la granulometría de las inclusiones (Druc \& Gwyn, 1998). Lo observan también Burger \& Salazar (2015: 46) en la cerámica de Coscopunta.

Vale recordar que en la región de Huari, la alfarera produce formas bien estandarizadas, pero la preparación de la pasta está a cargo de ayudantes o peones no especializados. Esto puede introducir una variabilidad en la pasta. En 
este caso, la variabilidad de composición de las materias primas o del tamaño de las inclusiones no depende de la maestría de la alfarera. Su competencia se nota en la regularidad de la forma pero también en el alineamiento de las inclusiones y la distribución homogénea de las mismas. Cabe notar que la acción de alisar o pulir orienta las inclusiones próximas a la superficie paralelamente al borde sin influir necesariamente sobre la orientación de las inclusiones en el centro de la pasta. En las láminas de Marcajirca se ve un alineamiento en las muestras Ma3, Ma5, Ma6, Ma7, Ma10, Ma12, y falta de orientación para las láminas Ma4, Ma8, Ma9, Ma11. En la muestra Ma1 se observa una tendencia mixta, con solo los fragmentos más grandes alineados en forma paralela al borde.

- Origen diferente de la cerámica Ma10: la muestra Ma10 es la única muestra que difiere en composición del resto del conjunto analizado. La cantidad de shashal es menor que en otras cerámicas y el tamaño de estos fragmentos es más controlado. El componente principal consiste en fragmentos graníticos. Esta composición sugiere un lugar de producción diferente al de las otras muestras, con una receta de pasta distinta a lo visto en Marcajirca. Parece pertenecer a otra tradición tecnológica, quizá fuera del valle del Huaritambo. Sin embargo, la presencia de shashal denota un lugar de producción donde la tradición de usar pizarra molida está vigente. También, el shashal ha podido ser agregado a la pasta en caso de una producción por un alfarero itinerante que utilizó una combinación de materiales (de su lugar de origen y del lugar donde produce). La pasta presenta inclusiones gruesas, indicación de una preparación sin cernido fino. La mayoría de los cuarzos en la matriz tienen el mismo aspecto que los cuarzos en los fragmentos graníticos y las areniscas cuarzosas, lo que sugiere un origen derivado de estas rocas. A pesar de su pasta distinta, este fragmento no se distingue en su apariencia externa de los otros fragmentos elegidos.

A modo de comparación, la figura 6 (E-F) ilustra pastas típicas con temperante de shashal de cerámicas tradicionales en Mallas y Acopalca.

\section{ESCENARIO DE PRODUCCIÓN: HIPÓTESIS DE PROCEDENCIA}

Varios factores impactan negativamente la posibilidad de producción cerámica en Marcajirca. El sitio no cuenta con arcilla de buena calidad (que sepamos), minas de shashal o fácil acceso a fuentes de agua. Hay también menos horas de calor por día para secar las ollas. El mismo problema de adquisición y conservación del agua está mencionado para los sitios de Puruhuay, donde diversas estrategias fueron implementadas, como reservorios y vasijas para recolectar agua (Orsini \& Benozzi, 2013: 44). Tampoco se encontró en Marcajirca evidencias de producción, herramientas, deshechos o sitios de quema. En consecuencia, se propone una producción epilocal, intravalle, posiblemente en la zona de Yacya/Acopalca a $8 \mathrm{~km}$ de Marcajirca, cerca de las fuentes de materiales. Se postula la existencia de una red de distribución o intercambios desarrollados por los habitantes de los sitios altos como Marcajirca para obtener las vasijas. Otro escenario es una producción in situ por alfareros o alfareras itinerantes, yendo a los pueblos de 
altura desde la zona de Yacya/Acopalca, con sus materiales ya preparados, como se hace todavía (Druc, 2005: 67).

Este escenario se basa en la tradición alfarera de la región y la localización de los centros alfareros actuales. Aunque la presencia de buenos materiales para la producción no es siempre una condición para el desarrollo de la actividad alfarera (Arnold, 1985; Rice, 1987), el hecho de que solamente se concentra la producción alrededor de Mallas, Yacya y Acopalca, en la vertiente de la Cordillera, debe ser interpretado como la continuación de una tradición fuerte y antigua, en un sitio donde se encuentran buenos materiales. Además, estudios etnográficos muestran que los centros alfareros tienen una zona de aprovisionamiento dentro de un cierto radio, tomando en cuenta la topografía, la geología y los esfuerzos necesarios para conseguir las materias (Arnold, 1985). En el área de estudio, la zona de recursos se extiende hasta 10 km de la zona de producción (Druc, 1996; 2001). Esto significa que, para distinguir un centro productor de otro, deben ser localizados a más de $10 \mathrm{~km}$ el uno del otro, más aún si dos centros comparten los recursos, como en el caso de Yacya y Acopalca. En tiempos antiguos la situación ha podido ser distinta y los lugares de extracción pudieron estar más cerca de los pueblos alfareros. También, Yacya y Mallas tienen más antigüedad que el obraje de Acopalca y Santo Domingo de Huari, pueblo que resulta de una reducción en la época colonial (Márquez Zorrilla, 1965; Venturoli, 2009). Yacya y Mallas por lo tanto hubieran podido abastecer la región en vasijas durante el Intermedio Tardío. Acopalca ha podido jugar un papel en la producción y/o la distribución de las vasijas hasta Marcajirca, pero mayormente en la época colonial.

En relación con Marcajirca, la localización de estos centros tiene importancia. Mallas se encuentra en la otra vertiente, a $8 \mathrm{~km}$ (distancia geodésica) pero más lejos si se considera la distancia férica que toma en cuenta la topografía (Arnold, 1985: 33). Para llegar a Mallas o a Yacya desde Marcajirca se necesita bajar al valle, pasar el río Huaritambo y subir la otra vertiente, lo que representa probablemente un viaje de seis y cuatro horas respectivamente. Llegar a Acopalca es más fácil, caminando $8 \mathrm{~km}$ a flanco de montaña, unas dos horas y media a pie o menos. También, la distribución de cerámica y los intercambios deben haber sido más importantes en épocas antiguas, con puntos de intercambio de productos regionales en los valles.

\section{CONTEXTO EXTENDIDO DEL USO DE SHASHAL Y DE LA PRODUCCIÓN CERÁMICA EN EL INTERMEDIO TARDÍO EN CONCHUCOS}

El uso de shashal aparece en los niveles post-Chavín en Chavín de Huantar (Druc, 2001; John Rick, comunicación personal, 2000), pero no se generaliza antes del Intermedio Tardío, en particular en el tipo Negro grafito (Ibarra, 2003; Víctor Ponte comunicación personal, 1998; Porcedda, 2013). Esta cerámica se encuentra en un territorio extendido. En Conchucos, corresponde al territorio de los grupos huari y pincos (Ibarra, 2006; Léon Gómez, 2003). El uso de shashal también se nota en 
el 90\% de las cerámicas del Intermedio Tardío de Ñawpamarca de Huamantanga (Porcedda, 2013: 92). En San Marcos, Juntu Ama parece también tener cerámica con shashal (Porcedda, 2013: 92, nota 3).

Marta Porcedda (2013: 91) observa que la tradición tecnológica difundida en la región de Huari con uso de temperante de shashal y ciertas decoraciones se asemeja a la del Intermedio Tardío. Esta autora nota la similitud entre una decoración aplicada sobre una jarra tradicional de Acopalca y las aplicaciones en un fragmento de Ñawpamarca de Huamantanga y uno de Ishla Ranra (Orsini \& Benozzi, 2013: fig. 107, pp. 91, 95, 93, notas 5 y 6). El uso de shashal se ve también en fragmentos encontrados en Awilupaccha, Llamacoral y Ishla Ranra, todos en la región de Puruhuay (Orsini \& Belazzi, 2013).

Cabe mencionar que el uso de shashal no es universal para el Intermedio Tardío en Áncash. En la región de la cuenca del Yanamayo, en el sitio de Huacramarca (Vega Centeno, 2008) a $8 \mathrm{~km}$ de Chacas, un análisis macroscópico de cortes frescos de Huacramarca permitió reconocer tres grupos de composición: A) con cuarzos, feldespatos y trozos de cerámica; B) con una mayoría de rocas feldespáticas; y C) sin temperantes (para más detalles ver Vega Centeno et al., 2014: 3). Sin embargo, ningún grupo presenta fragmentos de shashal en la pasta, lo que indica la existencia de una tradición tecnológica distinta de la de Huari en el Intermedio Tardío. Es interesante notar que se utiliza shashal como temperante en la tradición cerámica actual de esta región, pero que estas inclusiones tienen un porcentaje de carbón menor que en la zona de Huari (Druc, 2001).

En Chinchawas en la Cordillera Negra, la cerámica de la fase Chakwas no está temperada con shashal pero presenta una pasta gruesa, formas y estilos decorativos similares a lo observado en Ñawpamarca, en Conchucos (Porcedda, 2013: 95). Las cerámicas de La Pampa en el norte del Callejón de Huaylas tampoco parecen contener pizarra molida (Porcedda, 2013: 95). Finalmente, el análisis formal y estilístico del conjunto de vasijas de Coscopunta por Burger \& Salazar (2015) en el Callejón de Huaylas, cerca de Anta pero en la vertiente de la Cordillera Negra, tiene correspondencia estilística con la cerámica tardía de Chinchawas. Siendo vasijas (quasi) enteras no se dispone de información acerca de la pasta. Sin embargo, es muy probable que, al igual que para Chinchawas-Chakwas, no se haya utilizado shashal como temperante.

Estas observaciones sugieren que se compartía de modo general un registro formal y decorativo en un área extensa de la sierra de Áncash, pero que existían muchas variantes locales (ver la discusión al respecto en Burger \& Salazar, 2015: 47-49). El uso de shashal como temperante sería una característica de la zona de Huari en Conchucos central en el Intermedio Tardío. Del punto de vista identitario, tanto Lau (2013: 33) como Burger \& Salazar (2015: 23) observan que la cerámica del Intermedio Tardío no tenía un carácter representativo de un grupo político o étnico. Sin embargo, la manera de producir las vasijas era propia de cada región o valle. Agregaría que el carácter intrínseco, invisible de una cerámica, es decir la composición de la pasta y el estilo técnico, puede ser un marcador identitario más seguro, aunque más sutil, que el estilo y la forma, como se ha demostrado 
para la tradición actual en las zonas de Huari y San Luis (Druc, 2009). Además si se considera que en el mundo andino se aceptaba la alteridad en un sentido necesario de complementariedad, como lo sugiere Lau (2013: 82-84), podemos pensar que la cerámica expresa estas dos percepciones de alteridad e identidad. De modo visible, la cerámica refleja la asimilación de estilos regionales con imitación de formas y decoraciones, pero de modo invisible (para una persona foránea) la identidad se manifiesta en la pasta, en el modo de hacer, en el estilo técnico. Este estilo se manifiesta también en detalles del acabado como el análisis de las vasijas de Coscopunta lo demuestra, donde se nota el carácter rústico, local y ocasional de la producción, a pesar de tener similitudes con otros alfares en la región (Burger \& Salazar, 2015: 45).

Es también muy probable que los sitios de una región participaban de una misma red de distribución. El trabajo de Ramón \& Bell (2013) sobre la distribución de la cerámica utilitaria subraya la necesidad de considerar una circulación importante de este tipo de vasija, en volumen y en distancias. Tal distribución implicaba contactos entre comunidades, los cuales podrían explicar las similitudes observadas entre los diversos estilos decorativos de la Sierra de Áncash (ver también Burger \& Salazar, 2015: 48). Al respecto, Ibarra menciona que Marcajirca se sitúa en la cercanía de dos cerros de carácter sagrado, las jircas de LLamoq y Wiñaj, que se relacionan según este autor (Ibarra, 2009) con jircas de los grupos huari y pincos. Fueron sitios de peregrinaje que habrán ocasionado movimiento de personas y quizás de comodidades, tales como cerámica. Se sabe que hubo intercambios de productos entre los dos grupos y León Gómez (2003: 463) menciona que los huaris obtenían alumbre y papas negras de los pincos. Parte de la red de intercambio debía pasar por Pomachaca en el valle abajo de Marcajirca, donde se unen los ríos Huaritambo y Mosna, y punto a partir del cual estas aguas se convierten en el río Puccha, lo cual marca el límite entre los territorios Huari y Pincos. Desde luego, los habitantes de Marcajirca han podido tener más contactos que los de la zona de Puruhuay, más al norte, con miembros del grupo Pincos. Cabe notar que las fuentes de shashal conocidas se encuentran en la jurisdicción de Acopalca, en territorio Huari y que las minas son explotadas desde hace tres generaciones por lo menos (Druc, 2005). Se puede postular que los alfareros huari y pincos utilizaban las mismas fuentes o que existían intercambios de materia prima o de vasijas.

Finalmente, hay que mencionar que un pequeño porcentaje de vasijas de los sitios alrededor de la laguna de Puruhuay tiene fragmentos de calcita como inclusiones predominantes o junto con el shashal (Porcedda, 2013). Estas inclusiones podrían ser naturales en los sedimentos utilizados por los alfareros. Se necesitaría material geológico comparativo y estudios de procedencia sobre estos sitios para confirmarlo. De igual modo se ve en algunas cerámicas del Intermedio Tardío, analizadas en Marcajirca, fragmentos sedimentarios (e.g. areniscas) o de bajo metamorfismo (e.g. cuarcitas) además del shashal. Esto ocurre también en las pastas actuales. Son inclusiones naturales en las arcillas explotadas por los alfareros. Cabe señalar que en una ocasión la autora vio un grueso fragmento 
de feldespato granítico en una pasta actual de Acopalca, lo que sugiere que este tipo de material puede encontrarse naturalmente en sedimentos de la zona. La presencia de shashal en estas muestras sugiere un origen local o epilocal, siendo la región de Acopalca una posibilidad. Como el conjunto analizado es pequeño, estas conclusiones son tentativas. La (pequeña) diferencia de composición entre las muestras del Intermedio Tardío y la época Inca podría indicar el uso de sedimentos arcillosos y lugares de producción diferentes, pero siempre en la misma región. La similitud de pasta de la muestra Ma6 de época Inca (si la atribución temporal es correcta) con pastas del Intermedio Tardío (Petrogrupo 1) indica que la tradición cerámica y la red de distribución de la época antes de la llegada de los Incas seguían vigentes. El único fragmento foráneo de este grupo de cerámicas de Marcajirca es Ma10 que por su composición sugiere una procedencia particular, posiblemente de otra parte de Conchucos central, pero donde la tradición de utilizar shashal también prevale.

\section{CONCLUSIONES}

Los análisis de las cerámicas de Marcajirca permitieron identificar varios grupos petrográficos. La mayoría pertenece a una misma tradición cerámica que se caracteriza por el uso de un temperante de pizarra molida. Esta tradición tecnológica está todavía en vigor en el área de estudio. Una muestra denota una procedencia distinta, con un estilo tecnológico que usa otra fuente de recursos y sedimentos con fragmentos de roca granítica probablemente derivados del batolito de la Cordillera Blanca. El área de producción de las cerámicas de Marcajirca todavía está en cuestión. Se postula un origen en la zona de Yacya/Acopalca para la mayoría de las cerámicas. La adquisición de las vasijas puede haber ocurrido por medio de intermediarios, en puntos de intercambio de mercadería más abajo en el valle o de modo directo al productor en la zona de Yacya o Acopalca. Estos centros de producción quedan a unos $8 \mathrm{~km}$ de Marcajirca y hubieran podido abastecer a todo el valle del Huaritambo. Los productores también han podido viajar para intercambiar sus ollas o proponer sus servicios. Una combinación de escenarios es posible. Que se trate de una distribución por los alfareros mismos o de la adquisición de las vasijas en el valle o en la zona de Huari, se postula que la mayoría de las cerámicas de Marcajirca pertenecen a una tradición regional particular a la zona de Huari. Esta tradición perduró hasta el presente y las minas de shashal en las alturas de Acopalca fueron ya utilizadas por los alfareros de la región en el Intermedio Tardío.

Por otra parte, varias interrogaciones quedan en cuanto a la producción cerámica en el Intermedio Tardío para la zona al sur y al este de Marcajirca, en el valle del Puccha. En el presente no se conoce producción alfarera en esta zona pero no se puede descartar esta posibilidad. Tampoco se conoce el papel que el grupo huari jugaba en relación con la producción cerámica y el abastecimiento de vasijas en el territorio Pinco al sur del río Puccha. En épocas históricas, productores de Yacya y Mallas iban a ofrecer sus vasijas del otro lado del río Puccha, en los caseríos 
La cerámica tardía de Marcajirca, Conchucos, Áncash: lo que nos enseñan los estudios petrográficos

de Castilli y Jirca, arriba del puente de Pomachaca en territorio Pinco, a $13 \mathrm{~km}$ a vuelo de pájaro (Druc, 2005). Para profundizar este tema se necesita una muestra más amplia incluyendo cerámica encontrada en territorio Pinco. Finalmente, un análisis químico con espectrometría de masa de la matriz arcillosa de las cerámicas de Marcajirca sería útil para confirmar o rechazar la hipótesis de una procedencia de la zona Yacya/Acopalca. En cuanto a los análisis con el MEB, los resultados son interesantes pero preliminares y se necesita un mejor conocimiento de la composición y variabilidad de las minas de pizarra a nivel local y regional para poder seguir con estudios de procedencia del temperante.

\section{Agradecimientos}

Estoy muy agradecida con Bebel Ibarra, quien me proporcionó los fragmentos de cerámica de Marcajirca, informaciones acerca del sitio, mapas y un presupuesto por la preparación de las láminas. Agradezco a John Fournelle de la Universidad de Wisconsin-Madison por su ayuda con el MEB, al departamento de Geología por permitirme usar el microscopio petrográfico y a Jim Stoltman, del departamento de Antropología, por el acceso a su microscopio con equipo fotográfico. Finalmente quiero agradecer a los revisores de este artículo que me motivaron a extender su alcance para lograr una perspectiva más amplia de la producción cerámica en Conchucos. Agradezco también a Carolina Orsini y George Lau para los datos que me proveyeron acerca de sus investigaciones.

\section{Referencias citadas}

ARNOLD, D. E., 1985 - Ceramic theory and cultural process, xi + 268 pp.; Cambridge: Cambridge University Press.

BURGER, R. L., 1982 - Pojoc y Waman Wain. Two Early Horizon villages in the Chavín heartland. Nawpa Pacha, 20: 3-40.

BURGER, R. L. \& SALAZAR, L. C., 2015 - La cerámica de Coscopunta, un sitio del Periodo Intermedio Tardío en la provincia de Carhuaz, Callejón de Huaylas, Perú. Bulletin de l'Institut Français d'Études Andines, 44 (1): 23-52.

COBBING, J., AGAPITO, S. F., WILLIAM MARTÍNEZ, V. \& ZÁRATE, H. O., 1996 - Geología de los cuadrangulos de Huaraz, Recuay, La Unión, Chiquian y Yanahuanca, 281 pp.; Lima: Instituto Geológico Minero y Metalúrgico.

COBBING, J., PITCHER, W. S., WILSON, J. J., BALDOCK, J. W., TAYLOR, W. P., MCCOURT, W. \& SNELLING, N. J., 1981 - The geology of the Western Cordillera of Northern Peru, $x+143$ pp.; Londres: Institute of Geological Sciences.

DIESSL, W., 2004 - Huantar, San Marcos, Chavín. Catastro de sitios arqueológicos, 582 pp.; Lima: Instituto Cultural Runa.

DRUC, I., 1996 - De la etnografía hacia la arqueología: aportes de entrevistas con ceramistas de Ancash (Perú) para la caracterización de la cerámica prehispánica. Bulletin de l'Institut Français d'Études Andines, 25 (1): 17-41. 
DRUC, I., 1998 - Ceramic production and distribution in the Chavín sphere of influence (north-central Andes), vi +121 pp.; Oxford: British Archaeological Reports, Hadrian Books.

DRUC, I., 2001 - Shashal o no shashal, esa es la cuestión. Etnoarqueología cerámica en la zona de Huari, Ancash. Bulletin de l'Institut Français d'Études Andines, 30 (1): 157-173.

DRUC, I., 2004 - Ceramic Diversity in Chavín de Huantar. Latin American Antiquity, 15 (3): 344-363.

DRUC, I., 2005 - Producción alfarera y etnoarqueología en Conchucos, Ancash, Perú, 110 pp.; Lima: Instituto Cultural Runa.

DRUC, I., 2009 - Tradiciones alfareras, identidad social y el concepto de etnias tardías en Conchucos, Ancash, Perú. Bulletin de l'Institut Français d'Études Andines, 38 (1): 87-106.

DRUC, I., 2011 - Tradiciones alfareras del valle de Cajamarca y cuenca alta del Jequetepeque, Perú. Bulletin de l'Institut Français d'Études Andines, 40 (2): 307- 331.

DRUC, I. \& GWYN, H., 1998 - From clay to pots: A petrographic analysis of ceramic production in the Callejón de Huaylas, North-Central Andes, Peru. Journal of Archaeological Science, 25 (7): 707-718.

EGELER, C. G. \& De BOY, T., 1956 - Geology and petrology of part of the southern Cordillera Blanca, Peru. Geology Serie, 19 (1): 1-86.

FOLK, R. L., 1965 - Petrology of sedimentary rocks, 180 pp.; Austin: The University of Texas.

HERRERA, W. A., 2003 - Patrones de asentamiento y cambios en las estrategias de ocupación en la cuenca sur del Río Yanamayo, Callejón de Conchucos. In: Arqueología de la sierra de Ancash. Propuestas y perspectivas (B. Ibarra, ed.): 221-250; Lima: Instituto Cultural Runa.

HERRERA, W., ORSINI, C. \& LANE, K. (eds), 2006 - La complejidad social en la Sierra de Ancash, xix + 197 pp.; Milano, Lima: Civiche Raccolte d'Arte del Castello Sforzesco Raccolte Extraeuropee, Punku Centro de Investigación Andina.

IBARRA ASENCIOS, B., 2003 - Arqueología del valle del Puccha. In: Arqueología de la Sierra de Ancash (B. Ibarra Asencios, ed.): 252-330; Lima: Instituto Cultural Runa.

IBARRA ASENCIOS, B., 2006 - Ancestros y muerte durante la época prehispánica en la Sierra de Ancash: buscando nuestros antepasados. In: La complejidad social en la Sierra de Ancash: ensayos sobre paisaje, economía y continuidades culturales (A. Herrera W., C. Orsini \& K. Lane, eds.): 85-100; Milano, Lima: Civiche Raccolte d'Arte Applicata del Castello Sforzesco, Raccolte Extraeuropee, Punku Centro de Investigación Andina.

IBARRA ASENCIOS, B., 2007 - Excavaciones en los sitios de Llamacorral y Marcajirca en el valle del Puccha, Provincia de Huari-Ancash. Informe Temporada 2006. ms.

IBARRA ASENCIOS, B. (ed.), 2009 - Historia prehispánica de Huari: 3000 años de historia desde Chavín hasta los Inkas, 257 pp.; Huari: Instituto de Estudios Huarinos.

LANNING, E. P., 1965 - Current research: Highland South America. American Antiquity, 31: 139-140.

LAU, G., 2002 - Feasting and ancestor veneration at Chinchawas, North Highlands of Ancash, Peru. Latin American Antiquity, 13 (3): 279-304.

LAU, G., 2004 - The Recuay culture of Peru's North-Central Highlands: A reappraisal of chronology and its implications. Journal of Field Archaeology, 29 (1/2): 177-202.

LAU, G., 2005 - Core-Periphery relations in the Recuay hinterlands: economic interaction at Chinchawas, Peru. Antiquity, 79 (303): 78-99. 
La cerámica tardía de Marcajirca, Conchucos, Áncash: lo que nos enseñan los estudios petrográficos

LAU, G., 2010 - House forms and Recuay culture: Residential compounds at Yayno (Ancash, Peru), a fortified hilltop town, AD 400-800. Journal of Anthropological Archaeology, 29: 327-351.

LAU, G., 2013 - Ancient alterity in the Andes. A recognition of others, xiv +200 pp.; London, New York: Routledge.

LEÓN GÓMEZ, M., 2003 - Espacio geográfico y organización social de los grupos étnicos del Callejón de Conchucos durante los siglos XVI y XVII. In: Arqueología de la Sierra de Ancash (B. Ibarra Asencios, ed.): 457-466; Lima: Instituto Cultural Runa.

MANTHA, A., 2006 - Late Prehispanic Social Complexity in the Rapayan Valley, Upper Marañon Drainage, Central Andes of Peru. In: La complejidad social en la Sierra de Ancash: ensayos sobre paisaje, economía y continuidades culturales (A. Herrera Wassilowsky, C. Orsini \& K. Lane, eds.): 35-61; Milano, Lima: Civiche Raccolte d'Arte Applicata del Castello Sforzesco, Raccolte Extraeuropee, Punku Centro de Investigación Andina.

MARSH, L. \& DRUC, I., 2015 - Sampling paste for thin section: An Andean case study of the initial steps of petrographic research. In: Ceramic Analysis in the Andes (I. Druc, ed.): 157-170; Blue Mounds: Deep University Press.

MATOS COLCHADO, S., 2000 - Huaylas y Conchucos en la historia regional, 318 pp.; Lima: San Marcos.

MÁRQUEZ ZORRILLA, S., 1965 - Huari y Conchucos, 137 pp.; Lima: Ediciones Opulares.

ORSINI, C., 2005 - Arqueología de Chacas. Patrones de asentamiento en un valle de los Andes Centrales del Perú; Bolognia: Universitá degli Studi di Bolognia. Tesis doctoral.

ORSINI, C., \& BENOZZI, E., 2013 - Archaeology of an Andean Pacarina. Settlement patterns and rituality around Lake Puruhuay, Ancash, Peru, 155 pp.; Oxford: British Archaeological Reports.

PORCEDDA, M., 2013 - Description of finds: 5.1 Ceramic assemblage from Puruhuay. In: Archaeology of an Andean Pacarina. Settlement patterns and rituality around Lake Puruhuay, Ancash, Peru (C. Orsini \& E. Benozzi, eds.): 91-98; Oxford: British Archaeological Reports.

RAMÓN, G., 2013a - Los alfareros golondrinos. Productores itinerantes en los Andes, 167 рp.; Lima: Instituto Francés de Estudios Andinos, Sequilao.

RAMÓN, G., 2013b - Las fuentes del estilo: distribución regional de canteras y técnicas alfareras en Conchucos (Ancash, Perú). Bulletin de I'Institut Français d'Études Andines, 42 (1): 49-90.

RAMÓN, G. \& M. BELL, 2013 - Re-placing plainware: Production and distribution of domestic pottery and the narration of the pre-colonial past in the Peruvian Andes. Journal of Anthropological Archaeology, 32: 595-613.

RICE, P., 1987 - Pottery Analysis: A Sourcebook, xxiv + 559 pp.; Chicago: The University of Chicago Press.

ROUX, V., 2003 - Ceramic standardization and intensity of production: Quantifying degrees of specialization. American Antiquity, 68 (4): 768-782.

VEGA CENTENO, R., 2008 - El proyecto de investigación arqueológica Huacramarca. Resultados preliminares. Investigaciones Sociales, 12 (21): 49-75.

VEGA CENTENO, R., TRUJILLO QUINDE, A. L., MEJÍA SANTILLÁN, M. E. \& BRAVO CABREJOS, J. A., 2014 - Análisis composicional de la cerámica de Huacramarca, cuenca sur del Yanamayo, Ancash. Investigaciones Sociales, 18 (32): 57-72. 
VENTUROLI, S., 2009 - Acopalca y Yacya: Origen de dos comunidades huarinas. In: Historia prehispánica de Huari: desde Chavín hasta los Inkas: 3000 años de historia (B. Ibarra Asencios, ed.): 241-254; Huari: Instituto de Estudios Huarinos.

WEGNER, S., 2000 - Arqueología y arte antiguo de Chacas, 19 pp.; Chacas: Municipalidad de Chacas.

WEGNER, S., 2011 - Iconografías prehispánicas de Ancash: cultura Recuay. Tomo II; Lima: Asociación Ancash. 